\title{
Türkiye'de Çevresel Kuznets Hipotezi ve Yenilenebilir Enerji Tüketiminin Karbon Salımı Üzerine Etkisi: Yapısal Kırılmalı Eşbütünleşme Yaklaşımı*
}

\author{
Abdullah Emre ÇAĞLAR**
}

\author{
Mehmet MERT ${ }^{* * *}$
}

\begin{abstract}
$\ddot{O} Z$
Çalışmanın amacı çevresel Kuznets hipotezini sinamak ve yenilenebilir enerji tüketimi ile sera gazı salımı arasındaki ilişkiyi ortaya çıkarmaktır. Bu amaçla; karbondioksit emisyonu, gayri safi yurtiçi hasıla ve yenilenebilir enerji kaynakl elektrik tüketimi değişkenleri kullanılarak 1960-2013 dönemi için seriler elde edilmiş; tek ve çift yapısal kırılmalı birim kök testleriyle beraber yapısal kırılmaya izin veren eşbütünleşme analizleri ile seriler arasındaki uzun dönem ilişkinin varlığı tespit edilerek dinamik en kü̧̈ük kareler yöntemi ile uzun dönem denge ilişkisi tahmin edilmiştir. Analiz sonucunda yenilenebilir kaynaklı enerji tüketiminin sera gazı salımını azalttığı sonucuna ulaşılmıştır. Ayrıca Türkiye'de, Çevresel Kuznets hipotezinin geçerli olduğu ekonometrik yöntemlerle belirlenmiștir.

Anahtar Kelimeler: Birim Kök; Yapısal Kırllma; Eşbütünleşme; Çevresel Kuznets Eğrisi.

JEL Sinıflandirması: C32, Q43, Q56

Environmental Kuznets Hypothesis and The Impact of Renewable Energy Consumption on Carbon Emmissions in Turkey: Cointegration with Structural Breaks Approach
\end{abstract}

\section{ABSTRACT}

The aims of study are to reveal that how renewable energy consumption impacts on the GHG emissions and test the environmental Kuznets curve hypothesis for Turkey. For this purposes, series of $\mathrm{CO}_{2}$ emissions, GDP and electricity generated using renawebles between 1960 and 2013 are used. The unit root tests with structural breaks have been performed and cointegration tests have been used. Finally, DOLS estimation method has been used to find out long run relationship. Model results show that renewable electricity production has negative and significant effects on the carbon emmissions and results supported the validity of Environmenal Kuznets Curve hypothesis for Turkey.

Key Words: Structural Breaks, Cointegration, Environmental Kuznets Curve, Renewable Energy.

JEL Classification: C32, Q43, Q56

\section{GİRIŞ}

Son iki yüzyıl içerisinde fosil yakıtlar 1973 yılında gerçekleşen petrol krizine kadar oldukça yaygın bir şekilde kullanılmaktaydı. Fakat petrol krizi ile birlikte enerji kaynakları ile ilgili güvensiz bir ortam oluşmaya başlamıştır. Fosil yakıtlardan kaynaklanan bu güvensizlik, bütün dünyada yenilenebilir enerji kaynaklarına doğru bir yönelimi getirmiştir. Enerji kaynaklarının güvenliğinin

\footnotetext{
* Bu çalışma Aydın'da düzenlenen EUREFE'16 konferansında sunulmuş şeklinin yeniden gözden geçirilmiş ve genişletilmiş biçimidir.

** Arş. Gör. Akdeniz Üniversitesi İİBF, Ekonometri Bölümü, aecaglar@akdeniz.edu.tr;emreacaglar@gmail.com

**** Doç. Dr. Akdeniz Üniversitesi İ̈BF, Ekonometri Bölümü, mmert@akdeniz.edu.tr
} 
sağlanması gerekliliği nedeniyle enerji politikalarının en önemli kalemlerinden biri enerji çeşitliliği konusu olmuştur. Ayrıca günümüzde artan doğalgaz ve petrol fiyatları da enerji çeşitliliği başlığını ön plana çıkarmaktadır. Bu nedenlerden dolayı yenilenebilir enerji kaynakları enerji çeşitliliğini arttırmakta ve bu alana yönelim hızla artmaktadır. Yenilenebilir enerji kaynaklarına yönelim 90’l1 y1llarda çevre bilincinin ortaya çıkmasıyla artmıştır. Fosil yakıt kaynaklı geleneksel enerji üretimi ve tüketimi, bölgesel ve küresel seviyede sera gazı salımını arttırdığı için küresel 1sınmaya ve nihayetinde iklim değişikliğine neden olmaktadır. Dolayısıyla en azından üretim aşamasında atmosfere sera gazı emisyonu vermeyen yenilenebilir kaynaklı enerjiler "temiz enerji” olarak nitelendirilmektedir (Çağlar, 2006: 1).

21. yüzyılda güvenli enerji tedariği dünyanın karşılaştığı en büyük sorunlardan birini oluşturmaktadır. Günümüzde ülkelerin enerji üretimi ve kullanımı sürdürülebilir değildir. Sürdürülebilir olmayan enerji üretimi ve kullanımının en önemli sonucu insan kaynaklı çevreye verilen zararlardır. Bu olumsuz etki iklim değişikliği olarak karşımıza çıkmaktadır. Enerji tüketiminin 1990-2008 yılları arasında \%40 arttığı dünyada enerji kullanımının \%80’i fosil kaynaklıdır. Bu denli yüksek oranda fosil yakıt kullanımı ülkelere ve dünyaya olumsuz etkileri olacaktır. Dolayısıyla ülkelerin fosil yakıt kullanmaları hem ekonomiye bağımlılık getirmekte hem de atmosfere yayılan sera gazı miktarında artışa neden olmaktadır (WWF, 2011: 2).

Çevresel Kuznets Eğrisi (bundan sonra, ÇKE) ekonomik büyüme ile çevresel kirlenme arasındaki ilişkiyi göstermektedir. Teorinin asıl çıkış noktası, Kuznets'in (1955) çalışmasında gelir dağılımı ile ekonomik büyüme arasında tersU şeklinde bir ilişkinin varlığını kanıtlamasıyla ortaya çıkmıştır. Daha sonra bu yaklaşım çeşitli yazarlar tarafından geliştirilerek kişi başına gelir değişkeni ile çevre kirliliği değişkenleri kullanılmaya başlanmıştır. Bu yaklaşıma göre, çevresel kirlilik ekonomik büyüme ile birlikte artmaya başlamaktadır. Fakat bir eşik değerinden sonra ekonomik büyüme artarken çevresel kirlilik giderek azalma eğilimine girmektedir. Bu yaklaşım, ekonomik büyüme ile çevresel kirlilik arasındaki ilişkinin ters-U biçiminde olduğunu ifade etmektedir (Grossman ve Grueger, 1995: 2- 3). Dolayısıyla ekonomik büyüme devamlı bir çevresel kirliliği getirmemektedir. Aksine belli bir gelir düzeyine ulaşınca çevresel kirlenme giderek azalmaktadir.

Çalışmanın giriş bölümünden sonra gelen ikinci bölümünde ilgili literatür özetlenerek çıkarımlar yapılacaktır. Daha sonra üçüncü bölümde kullanılacak ekonometrik yöntemler açıklanacak, dördüncü bölümde amprik bulgular elde edilecek ve sonuç bölümünün yer aldığı son bölümde ise tüm bulgular literatür çerçevesinde yorumlanarak politika önerileri sunulacaktır.

\section{LITERATÜR TARAMASI}

Çevre bilincinin artması ve doğanın tahrip edilmesinin geri dönüşü olmayan zararlar doğuracağının insanoğlu tarafından fark edilmesi ile birlikte araştırmacılar doğanın korunmasına yönelik çalışmalarını arttırmaktadır. Son dönemlerde iklim değişikliği ve küresel 1sınma sorunlarıyla nasıl başa çıkılması gerektiğini araştıran çalışmalarda ÇKE yaklaşımı önemli bir yer edinmektedir. İlk 
defa Grossman ve Krueger (1991) tarafından ortaya atılan bu düşünceye göre ekonomik büyüme öncelikle çevresel tahribata neden olmakta fakat ülkenin kişi başına düşen milli geliri belirli bir eşik değerine ulaştıktan sonra çevresel tahribat azalma eğilimine giderek süreç tersine doğru işlemektedir. Yani bu eşik değerinden sonra kişi başına düşen milli gelir artarken, çevreye verilen hasarlar azalmaktadır. Şekil 1'de ÇKE'nin çalışma prensibi gösterilmektedir.

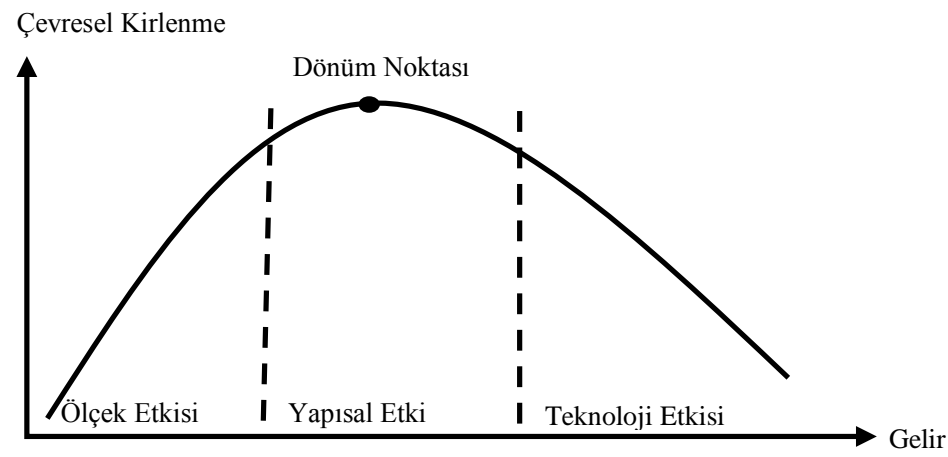

Şekil 1. Çevresel Kuznets Eğrisi (Kaynak: Bilgili vd. , (2015): 839)

ÇKE'ne göre kişi başına gelir ile çevresel kirlenme arasında ters-U şeklinde bir ilişki vardır [Grossman ve Krueger (1991,1995); Stern (1994); Dinda (2004)]. ÇKE yaklaşımında gelirin yükselmesi ile ilk olarak çevresel kirlenme artacaktır. Fakat belli bir dönüm noktasına ulaşılınca, çevresel kirlenme gelirle ters orantılı biçimde azalacaktır. [Panayotou (1993); Selden ve Song (1994); Stern vd. (1996); Suri ve Chapman (1998); Soytaş vd. (2007); Managi ve Jena (2008); Halıcıoğlu (2009)]. Aslında bu süreç çok uzun zaman içerisinde tamamlanacaktır. Çünkü ÇKE oldukça uzun dönemde gerçekleşen bir olaydır (Dinda, 2004: 434). Literatürde ÇKE yaklaşımını açıklamaya yönelik birkaç teori vardır. Bunlar şekil 1'de görüldüğü gibi ölçek etkisi, yapısal etki ve teknoloji etkisidir.

Ölçek etkisine göre, teknoloji veri iken, daha fazla üretim yapılması doğal kaynak kullanımını arttırarak çevresel tahribatlara neden olmaktadır. Ekonomik büyüme patikasının ilk düzeylerinde daha fazla üretim yapabilmek için girdinin de artması gerekmektedir. Yani üretim arttıkça bununla paralel olarak girdi olarak kullanılan doğal kaynak tüketimi de artacaktır. Bununla birlikte üretim sürecinin doğal bir sonucu olarak atık maddeler oluşmakta ve bu zararlı maddelerin de doğayı tahrip edici özelliği yüksek derecede olmaktadır (Bilgili vd. , 2015: 839). Dolayısıyla ölçek etkisinin çevre kirliliği üzerinde negatif bir etkiye sahip olduğu görülmektedir (Managi ve Jena, 2008: 439).

Yapısal etki, ekonomik büyüme ile birlikte yapısal bir dönüşüme giren ülkede sürekli ekonomik büyüme çevreyi olumlu etkilemektedir. Diğer bir ifadeyle, büyüme ile birlikte ekonomi de bir dönüşüm gerçekleşmektedir ve bu dönüşüm ile birlikte ulusal üretim büyümekte ve gelişmektedir. Bunun sonucu olarak çevreyi daha az kirleten ekonomik faaliyetlerin payı giderek artmaktadır. Bunlara ek olarak, ülke ekonomisi sermaye yoğun sanayi sektörden hizmet sektörüne ve buradan da teknoloji yoğunluklu bilgi ekonomisine geçerek yapısal dönüşümünü 
tamamlayacaktır. Teknolojiyi yoğun olarak kullanan ülke ekonomileri daha az doğal kaynak kullanarak çevresel hasarların azaltılmasını sağlayacaktır. Burada, ülke ekonomisinin yapısal dönüşümdeki son aşaması bilgi ekonomisine ulaşmak olacaktır (Bilgili vd., 2015: 839).

Son olarak teknolojik etki ise, ülke ekonomisindeki gelişmeler üretim sanayisindeki gelişimi de beraberinde getirmektedir. Çevreyi kirletmeyen teknolojik gelişmeler sayesinde çevreye verilen hasarlar en aza indirilmektedir (Azam ve Khan, 2016: 558). Bu aşamaya gelen ülkelerde doğal kaynaklar optimal şekilde kullanıldığından dünya kaynakları etkin bir şekilde işlenmektedir. Ayrıca ekonomik refahla birlikte gelen teknolojik gelişmeler hem üretim maliyetlerini düşürmekte hem de atmosfere yayılan zararlı gazların azaltılmasını sağlamaktadır.

Enerji ve çevre literatüründe ÇKE yaklaşımı oldukça yaygın bir şekilde kullanılmaktadır. Son dönemlerde bu çalışmaların sayısı artarak hem enerji alanında hem de çevresel hasarların azaltılması konusunda önemli politika önerileri sunmaktadır. Bu çalışmalarda genellikle çevresel kirlenme bağımlı değişken olarak belirlenirken, kişi başına milli gelir, fosil kaynaklı veya yenilenebilir kaynaklı enerji tüketimi açıklayıcı değişken olarak belirlenmektedir. Çevresel kirlenmenin göstergeleri olarak yaygın olarak $\mathrm{CO}_{2}, \mathrm{SO}_{2}, \mathrm{NO}_{x}$, vd. değişkenler tercih edilmektedir [Panayotou (1993); Selden ve Song (1994); Bruyn vd. (1996); Bölük ve Mert (2015)]. Ayrıca ÇKE yaklaşımda birinci, ikinci veya üçüncü dereceden denklemler kullanılmaktadır.

Tablo 1'de ÇKE hipotezinin geçerliliğini araştıran çalışmalar gösterilmektedir. Bu çalışmalar, veri setlerine, bağımlı ve bağımsız değiş̧kenlere, kullanılan denklem derecesine göre değişiklik göstermektedir. Çalışmalarda bağımlı değişken olarak çevresel kirlenme göstergesi kullanılıyorken, enerji tüketimi göstergesi olarak da toplam enerji tüketimi, fosil kaynaklı enerji tüketimi veya yenilenebilir kaynaklı enerji tüketimi değişkenleri tercih edilmektedir. Ayrıca bazı çalışmalarda dış ticaret açığı ve doğrudan yabancı yatırımlar değişkenlerini de modele açıklayıcı değişken olarak eklenmektedir [Haisheng vd. (2005); Jalil ve Mahmud (2009); Baek vd. (2009); Kim ve Baek (2011); Ahmed ve Long (2012); Saboori vd. (2012); Lau vd. (2014); Mert ve Bölük (2016)].

Tablo 1. Literatür Özeti*

\begin{tabular}{|c|c|c|c|c|}
\hline Çalışma & Ülke & Veri Seti & Model & $\begin{array}{l}\text { EKC Geçerli } \\
\text { mi? }^{* *}\end{array}$ \\
\hline Haisheng vd. (2005) & Çin'de 30 Eyalet & $1990-2002$ & İkinci Dereceden & V \\
\hline Ang (2007) & Fransa & $1960-2000$ & İkinci Dereceden & V \\
\hline Başar ve Temurlenk (2007) & Türkiye & $1950-2000$ & Üçüncü Dereceden & $x$ \\
\hline Lise ve Montfort (2007) & Türkiye & $1970-2003$ & İkinci Dereceden & $x$ \\
\hline Akbostancı vd. (2009) & Türkiye & $1968-2003$ & Üçüncü Dereceden & $x$ \\
\hline Baek vd. (2009) & $\begin{array}{c}\text { Gelişmiş ve } \\
\text { Gelişmekte olan } \\
50 \text { Ülke }\end{array}$ & $1960-2000$ & Birinci Dereceden & V \\
\hline Halıcıoğlu (2009) & Türkiye & $1960-2005$ & İkinci Dereceden & V \\
\hline Jalil ve Mahmut (2009) & Çin & $1975-2005$ & İkinci Dereceden & V \\
\hline
\end{tabular}




\begin{tabular}{|c|c|c|c|c|}
\hline $\begin{array}{l}\text { Fodha ve Zaghoud (2010) } \\
\text { Iwata vd. (2010) }\end{array}$ & $\begin{array}{l}\text { Tunus } \\
\text { Fransa }\end{array}$ & $\begin{array}{l}1961-2004 \\
1960-2003\end{array}$ & $\begin{array}{l}\text { Üçüncü Dereceden } \\
\text { İkinci Dereceden }\end{array}$ & $\begin{array}{l}\mathrm{X} \\
\mathrm{V}\end{array}$ \\
\hline Arı ve Zeren (2011) & $\begin{array}{l}17 \text { Akdeniz } \\
\text { Ülkesi }\end{array}$ & $2000-2005$ & Üçüncü Dereceden & V \\
\hline Güriş ve Tuna (2011) & $\begin{array}{c}88 \text { Ülke } \\
\text { Gelişmiş ve }\end{array}$ & 1971-2008 & İkinci Dereceden & V \\
\hline Kim ve Baek (2011) & $\begin{array}{l}\text { Gelişmekte olan } \\
40 \text { Ülke }\end{array}$ & $1971-2005$ & Birinci Dereceden & V \\
\hline Ahmed ve Long (2012) & Pakistan & $1971-2008$ & Üçüncü Dereceden & V \\
\hline Saboori vd. (2012) & Endonezya & $1971-2007$ & İkinci Dereceden & $x$ \\
\hline Shahbaz vd. (2013) & Romanya & $1980-2010$ & İkinci Dereceden & V \\
\hline Dam vd. (2014) & Türkiye & $1960-2010$ & Üçüncü Dereceden & $x$ \\
\hline Lau vd. (2014) & Malezya & $1970-2008$ & İkinci Dereceden & V \\
\hline Bilgili vd. (2015) & 17 OECD Ülkesi & $1977-2010$ & İkinci Dereceden & V \\
\hline Mert ve Bölük (2016) & 21 Kyoto Ülkesi & $\begin{array}{l}\text { Dengesiz } \\
\text { panel }\end{array}$ & İkinci Dereceden & $x$ \\
\hline Bölük ve Mert (2014) & 16 AB Ülkesi & $1990-2008$ & İkinci Dereceden & $x$ \\
\hline Bölük ve Mert (2015) & Türkiye & $1961-2010$ & İkinci Dereceden & V \\
\hline
\end{tabular}

$\mathrm{Bu}$ çalışmada ise çevresel kirliliğin göstergesi olarak $\mathrm{CO}_{2}$ değişkeni kullanilırken, Panayotou (1993); Suri ve Chapman (1998); Agras ve Chapman (1999); Dinda vd. (2000); Jalil ve Mahmud (2009); Apergis ve Payne (2009); Shahbaz vd. (2013); Bilgili vd. (2015) çalışmaları takip edilerek ikinci dereceden denklem kullanılan model tercih edilmiştir.

\section{YÖNTEM}

Türkiye'de ekonomik krizler gibi çoğu toplumsal ve siyasi olaylar da makroekonomik değişkenler üzerinde etkili olmuştur. Bu etkiler zaman serisi değişkenlerinin ortalamasında, varyansında bazen de hem ortalaması hem de varyansında bir değişim meydana getirmektedir. Dolayısıyla bu etkiler dikkate alınarak analizlerde yapısal kırılmalı birim kök testleri ile yapısal kırılmalı eş bütünleşme testleri kullanılacaktır. Çalışmanın amprik analizi üç temel bölümden oluşmaktadır. Analizin ilk aşamasında değişkenlerin durağanlık özellikleri incelenecektir. Nelson ve Plosser (1982)'de belirtildiği gibi çoğu makroekonomik değişkenlerin düzeyde durağan olmadıkları bilinmektedir. Dolayısıyla beklentiler kullanılan değişkenlerin durağan olmaması yönünde olacaktır. Değişkenler düzey değerlerinde durağan olmayabilir. Fakat diğer değişkenlerle doğrusal kombinasyonlarında durağan hale gelebilirler. Yani bu değişkenlerin doğrusal bileşimi eşbütünleşik olabilmektedir. Bu nedenle analizin ikinci kısmında yapısal kırılmayı dikkate alan eşbütünleşme testleri kullanılacaktır. İlgili değişkenlerin eşbütünleşik olması durumunda ise, Stock ve Watson (1993) tarafindan önerilen Dinamik En Küçük Kareler (DOLS) yöntemi ile uzun dönem tahmin katsayıları elde edilecektir.

\section{A. Yapısal Kırılmalı Birim Kök Testleri}

Bir değişkene rassal bir şok geldiğinde bu şokun değişken üzerindeki etkisinin geçici olup olmaması ekonometrik çalışmalar için oldukça önemlidir. Çünkü değişken şokun etkisinden kısa zaman içerinde kurtulursa, yani şokun geçici olduğu görülürse $\mathrm{o}$ değişkenin birim kök içermediği (durağan olduğu) 
söylenilebilir. Zaman serilerinde bir serinin birim kök içerip içermediğini test eden birçok yöntem vardır. Bu konuda yapılan ilk çalışmalar Dickey ve Fuller (1979, 1981) tarafindan ortaya atılmıştır. Daha sonra Phillips ve Perron (1988); Kwiatkowski, Phillips, Schmidt, ve Shin (1992); Elliott, Rothenberg ve Stock (1996) gibi testler önerilmiştir. Fakat bu testlerin önemli bir dezavantajı vardır. Seride bir kırılma meydana geldiğinde, seri durağan olmasına rağmen bu testler kullanıldığında birim kök içerdiği sonucuna ulaşılabilmektedir (Perron, 1989: 1362). Zivot ve Andrews (1992), durağan olmayan birçok zaman serisinin yapısal kırılmaları dikkate alan testler kullanıldığında durağan olduğunu göstermişlerdir. Klasik birim kök testlerinin bu gibi dezavantajlarından dolayı yapısal kırılmaları dikkate alan birçok birim kök testi geliştirilmiştir. Çalışmada yapısal kırılmaları dikkate alan birim kök testlerinden ADF tipi tek kırılmalı Zivot ve Andrews (1992) (ZA) ve çift kırılmalı Narayan ve Popp (2010) (NP) testleri kullanılacaktır. Aşağıda bu testlerin veri yaratma süreçleri gösterilmektedir:

$$
y_{t}=\delta Z_{t}+e_{t} \text { ve } e_{t}=\beta e_{t-1}+\varepsilon_{t}
$$

Bu testlerin başlangıç noktası Eşitlik 1'deki gibi bir veri yaratma sürecinden oluşmaktadır. Daha sonra bu testler aşağıdaki gibi ADF prensibine göre oluşturulmaktadır:

$Z A$ ve NP yöntemlerinin test stratejilerinde tahmin edilen model:

$$
\Delta y_{t}=\hat{\delta} \Delta Z_{t}+\emptyset y_{t-1}+\sum_{j=1}^{k} \beta_{j} \Delta y_{t-j}+\varepsilon_{t}
$$

Eşitlik 2'deki modelde $Z_{t}$ dişsal değişkenler vektörüdür ve $Z_{t}$ 'nin çeşitli oluşturulma biçimlerine bağlı olarak ZA ve NP testleri ortaya çıkmaktadır.

$Z A$ testinde $Z_{t}$ dişsal değişkenler vektörü tek kırılmayı içerecek biçimde aşağıdaki gibi tanımlanmaktadır:

- $Z_{t}=\left[1, t, D_{t}\right]:$ sabitte tek kirilma (Model A)

burada, $t \geq T_{B}+1$ için $D_{t}=1$, diğer durumlar için 0 değerini almaktadır. $T_{B}$ yapısal kırılmanın zamanını belirtmektedir.

- $Z_{t}=\left[1, t, D_{t}, D T_{t}\right]:$ sabitte ve trende tek k1rilmaya (Model C)

burada, $t \geq T_{B}+1$ için $D T_{t}=t-T_{B}$, diğer durumlarda ise 0 değeri almaktadır.

$N P$ testinde $Z_{t}$ dışsal değişkenler vektörü çift kırılmayı içerecek biçimde aşağıdaki gibi tanımlanmaktadır:

- $Z_{t}=\left[1, t, D_{1 t}, D T_{1 t}\right]:$ sabitte çift kırılma (Model A)

burada, $\mathrm{j}=1,2$ iken $t \geq T_{B j}+1$ için $D_{j t}=1$, diğer durumlarda ise 0 değerini alır. $T_{B j}$, kırılmanın gerçekleştiği zaman periyodunu göstermektedir. 
- $Z_{t}=\left[1, t, D_{1 t}, D_{2 t}, D T_{1 t}, D T_{2 t}\right]:$ sabitte ve trende çift kırılma (Model C) burada, $t \geq T_{B j}+1$ için $D T_{j t}=t-T_{B j}$, diğer durumlarda ise 0 değerini almaktadir.

Ayrıca, 2 numaralı eşitlikte $\sum_{j=1}^{k} \beta_{j} \Delta y_{t-j}$ terimi ADF yaklaşımında otokorelasyon sorununu çözmek için regresyon modeline dahil edilmektedir. Burada, karşımıza optimal gecikme uzunluğu belirleme sorunu çıkmaktadır. Perron'a (1989) göre, k'nın optimal sayısına karar verebilmek için genelden özele yaklaşımından yararlanılması gerekmektedir. Maksimum sayıda gecikme ile başlanarak regresyonlar tahmin edilir ve kritik değere göre sıfır hipotezinin reddedildiği ilk gecikmede durulur. Böylece uygun gecikme sayısı belirlenmektedir (Ng ve Perron, 1995: 276-278).

Serinin durağan olup-olmadığını belirlemek için tanımlanan sıfır ve alternatif hipotezler şu şekildedir:

$H_{0}: \varnothing=0$, Birim kök vardır (durağan değildir)

$H_{1}: \varnothing<0$, Birim kök yoktur (durağandır)

Yapısal kırılmanın olmadığı durumda, hipotez testi için kullanılan test istatistiği aşağıdaki gibidir:

$\tau=t-\operatorname{stat}(\widehat{\varnothing})=\frac{\widehat{\phi}}{\operatorname{sh}(\widehat{\varnothing})}$

Burada, $\widehat{\varnothing}$ Eşitlik 2'de verilen modelin EKK tahmininden elde edilen parametre, sh ise bu parametreye ilişkin standart hatayı göstermektedir.

Yapısal kırılmanın olduğu durumda ise, ADF tipi test stratejini kullanan ZA ve NP için, Eşitlik 2'de verilen modelde, tek taraflı t-istatistiğini minimize eden $\tau$ değeri seçilmektedir:

$t_{\widehat{\phi}^{i}}\left[\hat{\tau}_{\text {inf }}^{i}\right]={ }_{\tau \in \Lambda}^{i n f} t_{\widehat{\phi}^{i}}(\tau), i=A, C$

Burada, $\wedge,(0,1)$ alt kümesinde belirlenmiştir. $T_{B}$ kırılma zamanı, olası kırılma noktaları için minumum (negatif) birim kök t-istatistiğini veren nokta olarak seçilmektedir (Çağlar, 2015: 16-19).

\section{B. Yapısal Kırılmalı Eşbütünleşme Testleri}

1. Gregory ve Hansen (1996) Testi

Gregory ve Hansen (1996) (GH), Engle ve Granger (1987) (EG) eşbütünleşme testine yapısal kırılmayı temsil eden kukla değişken ekleyerek yeni bir eşbütünleşme testi geliştirmiştir. Bazı amprik uygulamalarda, araştırmacılar durağan olmayan serilerin doğrusal kombinasyonunun durağan olma ihtimalini göz önünde bulundururlar. Böylece bu seriler eşbütünleşiktir şeklinde oluşturulan alternatif hipotez kabul edilebilmektedir. Fakat bu doğrusal kombinasyon örneklem boyunca bilinmeyen bir noktada değişime uğramış olabilir. Standart eşbütünleşme testleri bu karmaşıklığı açıklayamamaktadır. GH, bu karmaşıklığı ortadan kaldırmak için EG testinde açıklanan modele kırılmayı temsil eden kırılma kuklası eklemiştir. Bu testin diğer bir önemli özelliği ise, kırılma noktası önceden bilinmemektedir. Yani kırılma test stratejisi içerisinde içsel olarak 
belirlenmektedir. GH testi, düzeyde $(\mathrm{C})$, trend de $(\mathrm{C} / \mathrm{T})$ ve rejimde $(\mathrm{C} / \mathrm{S})$ tek kırılmaya izin verecek şekilde üç farklı modelden oluşmaktadır:

$y_{t}=\alpha_{1}+\alpha_{2} \vartheta_{1 \tau}+\delta_{1} y_{2 \tau}+e_{t}, t=1, \ldots, n$
$y_{t}=\alpha_{1}+\alpha_{2} \vartheta_{1 \tau}+b t+\delta_{1} y_{2 \tau}+e_{t}, t=1, \ldots, n$
$y_{t}=\alpha_{1}+\alpha_{2} \vartheta_{1 \tau}+\delta_{1} y_{2 \tau}+\delta_{2} y_{2 \tau} \vartheta_{1 \tau}+e_{t}, t=1, \ldots, n$

Eşitlik 5, 6 ve 7'deki modellerde, $\vartheta_{1 \tau}$ kırılma kuklasını temsil etmektedir ve aşağıdaki gibi tanımlanmaktadır:

$$
\vartheta_{1 \tau}=\left\{\begin{array}{l}
0, t \leq[n \tau] \\
1, t>[n \tau]
\end{array}\right\}
$$

Eşitlik 8'de, $\tau$ yapısal kırılma noktasını göstermekte ve aynı zamanda bilinmemektedir. [] işlemcisi ise yapısal kırılma noktasının tam sayı olmasını sağlamaktadır. Sıfır hipotezi, eşbütünleşme yoktur şeklinde kurulmaktadır. Hipotezlerin geçerliliğini sınamak için, $A D F^{*}, Z_{t}^{*}, Z_{\alpha}^{*}$ olmak üzere üç farklı test istatistiği hesaplanmaktadır. Test istatistiklerini hesaplarken eşitlik 5 ve 7 için her bir $\tau$ değeri En küçük kareler yöntemi ile tahmin edilir ve buradan kalıntılar $\hat{e}_{t \tau}$ serisi oluşturulur. Daha sonra yukarıdaki test istatistiklerini hesaplamak için birinci dereceden otokorelasyon katsayılarının hesaplanması gerekmektedir ${ }^{1}$ :

$\hat{\rho}_{t}=\frac{\sum_{t=1}^{n-1} \hat{e}_{t \tau} \hat{e}_{t+1 \tau}}{\sum_{t=1}^{n-1} \hat{e}_{t \tau}^{2}}$

Diğer aşamada, Phillips (1987) test istatistikleri için birinci dereceden otokorelasyon katsayılarının düzeltilmiş versiyonu elde edilir. Böylece kalıntılar $\hat{v}_{t \tau}=\hat{e}_{t \tau}-\hat{\rho}_{\tau} \hat{e}_{t-1 \tau}$ olarak yeniden düzenlenir. Sonraki aşamada otokovaryans toplamının ağırlıklandırılmış tahmini $\hat{\lambda}_{\tau}$ oluşturulur:

$\hat{\lambda}_{\tau}=\sum_{j=1}^{M} w\left(\frac{j}{M}\right) \hat{\gamma}_{\tau}(j)$

Burada, $\hat{\gamma}_{\tau}(j)=\frac{1}{n} \sum_{t=j+1}^{n} \hat{v}_{t-j \tau} v_{t \tau}$ ve $M=M_{n}$ olmak üzere bant genişliğinin seçimi için kullanılmaktadır. Sonuç olarak düzeltilmiş birinci dereceden otokorelasyon katsayıları tahmini oluşturulur: $Z_{\alpha}(\tau)=n\left(\hat{\rho}_{\tau}^{*}-1\right)$

$\hat{\rho}_{\tau}^{*}=\frac{\sum_{t=1}^{n-1}\left(\hat{e}_{t \tau} \hat{e}_{t+1 \tau}-\widehat{\lambda}_{\tau}\right)}{\sum_{t=1}^{n-1} \hat{e}_{t \tau}^{2}}$

\footnotetext{
${ }^{1}$ Daha ayrıntılı bilgi için bakınız, Gregory, A. W. ve Hansen, B. E. (1996). "Residual-Based Tests for Cointegration in Models with Regime Shifts". Journal of Econometrics, 70, 99-126.
} 
Yukarıdaki aşamalar izlenerek oluşturulmuş Phillips test istatistikleri:

$$
\begin{aligned}
& Z_{\alpha}(\tau)=n\left(\hat{\rho}_{\tau}^{*}-1\right) \\
& Z_{t}(\tau)=\frac{\left(\hat{\rho}_{\tau}^{*}-1\right)}{\hat{s}_{\tau}} \text { ve } \hat{s}_{\tau}=\frac{\widehat{\sigma}_{\tau}^{2}}{\sum_{1}^{n-1} \hat{e}_{t \tau}^{2}}
\end{aligned}
$$

ile belirlenmektedir. Son olarak üçüncü test istatistiği olan $A D F^{*}$ '1n nası1 hesaplandığ 1 gösterilecektir. Bu test istatistiği $\Delta \hat{e}_{t \tau}$ 'nun $\hat{e}_{t-1 \tau}$ ve $\Delta \hat{e}_{t-1 \tau, \ldots, \Delta \hat{e}_{t-K \tau}}$ üzerine regresyonundan elde edilmektedir. Burada $\mathrm{K}$ veri yaratma sürecinde serinin baştan ve sondan ne kadar kesileceğini göstermektedir. Sonuç olarak:

$A D F(\tau)=t-i s t\left(\hat{e}_{t-1 \tau}\right)$ olarak hesaplanmaktadır. Yukarıda oluşturulan üç istatistikte kendi aralarında en küçük değeri alan $A D F^{*}, Z_{t}^{*}, Z_{\alpha}^{*}$ istatistikleri ile seçilmektedir (Gregory ve Hansen, 1996: 102-106).

\section{Hatemi- J (2008) Testi}

Mevcut kırılmalı eşbütünleşme teorisinde tek olası rejim değişimini dikkate almaktadır. Hatemi-J (2008) (HJ) ise iki olası rejim değişimini dikkate alarak mevcut literatürü genişletmiştir. Testin dağılımı standart dağılıma uymadığı için, Monte Carlo Simülasyonları yardımıyla yeni kritik değerler üretmiştir. Aşağıda Engle ve Granger (1987) eşbütünleşme modeli verilmektedir:

$$
y_{t}=\alpha+\beta^{\prime} x_{t}+u_{t}
$$

Eşitlik 14'deki denkleme iki kırılma kuklası eklenerek HJ testi oluşmaktadır. Burada çift kırılmanın etkisi hem sabitte hem de eğimde (rejim değişimi) görülmektedir. $\mathrm{C} / \mathrm{S}$ olarak tanımlanan model aşağıda verilmektedir:

$$
y_{t}=\alpha_{0}+\alpha_{1} D_{1 t}+\alpha_{2} D_{2 t}+\beta_{0}^{\prime} x_{t}+\beta_{1}^{\prime} D_{1 t} x_{t}+\beta_{2}^{\prime} D_{2 t} x_{t}+u_{t}
$$

Eşitlik 15 'de $D_{1 t}$ ve $D_{2 t}$ kukla değişkenleri olarak tanımlanmaktadır ve aşağıdaki gibi oluşturulmaktadır:

$$
D_{1 t}=\left\{\begin{array}{l}
0, t \leq\left[n \tau_{1}\right] \\
1, t>\left[n \tau_{1}\right]
\end{array}\right\} \text { ve } D_{2 t}=\left\{\begin{array}{l}
0, t \leq\left[n \tau_{2}\right] \\
1, t>\left[n \tau_{2}\right]
\end{array}\right\}
$$

Eşitlik 16'da bilinmeyen parametre $\tau_{1}$ ve $\tau_{2}$ kırılma noktalarını göstermektedir. [] işlemcisi ise kırılma noktalarının tam sayı olmasını sağlamaktadır. Sıfır hipotezi eşbütünleşmenin olmadığı durumu göstermektedir. Sıfır hipotezini test etmek için üç farklı test istatistiği önerilmiştir. Bunlar, $A D F^{*}, Z_{t}^{*}, Z_{\alpha}^{*}$ olarak tanımlanmıştır. 
$Z_{\alpha}$ ve $Z_{t}$ test istatistikleri düzeltilmiş birinci dereceden otokorelasyon katsayıları tahmini olan $\hat{\rho}^{*}$ tarafindan hesaplanmaktadır²:

$\hat{\rho}^{*}=\frac{\sum_{t=1}^{n-1}\left(\widehat{u}_{t} \widehat{u}_{t+1}-\sum_{j=1}^{B} w(j / B) \widehat{\gamma}(j)\right.}{\sum_{t=1}^{n-1} \widehat{u}_{t}^{2}}$

Burada, w(.) spektral yoğunluk tahmincileri için standart koşulları sağlayan çekirdek ağırlıklandırılması ile elde edilmektedir ve B bant genişliğini gösterirken, $\hat{\gamma}(j)$ otokovaryans fonsiyonunu göstermektedir. Otokovaryans fonsiyonu:

$\hat{\gamma}(j)=\frac{1}{n} \sum_{t=j+1}^{T}\left(\hat{u}_{t-j}-\hat{\rho} \hat{u}_{t-j-1}\right)\left(\hat{u}_{t}-\hat{\rho} \hat{u}_{t-1}\right)$

Burada, $\hat{\rho}$ ise $\hat{u}_{t-1}$ 'in $\hat{u}_{t}$ üzerine (sabit terimsiz) regresonu En küçük kareler tahmini ile gösterilmektedir. Sonuç olarak $Z_{\alpha}$ ve $Z_{t}$ test istatistikleri:

$Z_{\alpha}=n\left(\hat{\rho}^{*}-1\right)$

$Z_{t}=\frac{\left(\widehat{\rho}^{*}-1\right)}{\left(\widehat{\gamma}(0)+2 \sum_{j=1}^{B} w(j / B) \widehat{\gamma}(j)\right) / \sum_{t=1}^{n-1} \widehat{u}_{t}^{2}}$

olarak hesaplanmaktadır. Burada, $\left(\hat{\gamma}(0)+2 \sum_{j=1}^{B} w(j / B) \hat{\gamma}(j)\right)$ terimi $\hat{u}_{t}{ }^{\prime}$ 'nin $\hat{u}_{t-1}$ üzerine regresyonundan elde edilen kalıntıların uzun dönem varyans tahminini göstermektedir ${ }^{3}$. Bu üç test istatistiği normal dağılmamaktadır. Ayrıca $A D F$ test istatistiğinin dağılımı ile $Z_{t}$ test istatistiğinin dağılımı benzer özellikler göstermektedir. Burada oluşturulan üç istatistikte kendi aralarında en küçük değeri alan $A D F^{*}, Z_{t}^{*}, Z_{\alpha}^{*}$ istatistikleri ile seçilmektedir (Hatemi- J, 2008: 498-500).

\section{VERİ VE AMPRÍK BULGULAR}

Çalışmada kullanılan veriler Dünya Bankası (World Bank) veri tabanından alınmıştır ${ }^{4}$. Türkiye için 1960 ve 2013 yılları arasında, kişi başına $\mathrm{CO}_{2}$ emisyonu (ton cinsinden), kişi başına gayri safi yurtiçi hasıla ( $\$$ cinsinden) (GSYH) ve kişi başına yenilenebilir enerji kaynaklı elektrik tüketimi (kWh cinsinden) (YEN) değişkenleri kullanılmıştır.

\footnotetext{
${ }^{2}$ Daha ayrıntılı bilgi için bakınız, Hatemi-J, A. (2008). "Tests for Cointegration with Two Unknown Regime Shifts with an Application to Financial Market Integration”. Empirical Economics, Volume:35, pp. 497-505. ${ }^{3}$ Ayrıntılı bilgi, Gregory ve Hansen (1996) tarafindan alıntılanan Andrews (1991) ve Andrews ve Monahan (1992) çalışmalarına bakınız. 
Tablo 2. 1960-2013 Yılları Arasında Bütün Değişkenler için Tanımlayıcı İstatistikler

\begin{tabular}{|l|l|l|l|l|l|}
\hline Değişkenler & Ortalama & Medyan & Minumum & Maksimum & Standart Sapma \\
\hline $\mathrm{CO}_{2}$ & 2.38 & 2.37 & 0.61 & 4.40 & 1.08 \\
\hline YEN & 10.51 & 3.80 & 0 & 128.569 & 24.03 \\
\hline GSYH & 4841.07 & 4530.65 & 2315.94 & 8716.68 & 1765.52 \\
\hline
\end{tabular}

Çalışmada kullanılan değişkenlere ait temel tanımlayıcı istatistikler Tablo 2'de gösterilmektedir. 1960-2013 yılları arasında Türkiye' de kişi başına düşen milli gelir ortalaması 4841.07\$ olmaktadır. Ayrıca en düşük GSYH değeri 2315.94\$ civarında geçekleşirken, en yüksek GSYH ise 8716.68\$ düzeyinde olduğu görülmektedir. YEN değişkeni incelendiğinde, Türkiye'de ortalama kişi başına $10.51 \mathrm{kWh}$ civarında yenilenebilir enerji tüketimi gerçekleşmektedir. Diğer yandan kişi başına düşen ortalama $\mathrm{CO}_{2}$ emisyon değeri 2.38 ton olarak gerçekleştiği görülmektedir.

Analizin ilk aşamasında değişkenlerin durağan olup olmadıkları ADF tipi yapısal kırılmalı ZA ve NP testleri ile incelenmiştir. Tablo 3'de değişkenlere ait durağanlık sonuçları verilmektedir.

Tablo 3. ZA ve NP Birim Kök Testlerinin Sonuçları

\begin{tabular}{|c|c|c|c|c|c|}
\hline & & \multicolumn{2}{|c|}{ ZA } & \multicolumn{2}{|c|}{$\mathrm{NP}$} \\
\hline & & Model A & Model C & Model A & Model C \\
\hline \multirow{3}{*}{$\mathrm{CO}_{2}$} & $T B_{1}$ & 2004 & 1999 & 1977 & 1979 \\
\hline & $T B_{2}$ & - & - & 2000 & 2000 \\
\hline & ADF-ist. & -4.310 & -4.497 & -4.469 & -6.819 \\
\hline \multirow{3}{*}{ YEN } & $T B_{1}$ & 1982 & 2005 & 1979 & 1977 \\
\hline & $T B_{2}$ & - & - & 1985 & 2007 \\
\hline & ADF-ist. & 1.678 & -3.979 & -1.380 & -4.514 \\
\hline \multirow{3}{*}{ GSHY } & $T B_{1}$ & 2002 & 2002 & 1978 & 1981 \\
\hline & $T B_{2}$ & - & - & 2004 & 2000 \\
\hline & ADF-ist. & -3.834 & -4.009 & -4.505 & -7.120 \\
\hline
\end{tabular}

Tablo 3'de tüm değişkenler tek ve çift kırılmalı iki teste göre de \%1 anlamlılık düzeyinde birim kök vardır sıfır hipotezi red edilememektedir. NP testinin $\mathrm{C}$ modelinde $\mathrm{CO}_{2}$ ve GSYH değikenlerinin durağan olduğu görünmektedir. Burada NP testinin güç ve boyut özellikleri incelenmelidir. NP testi için model A dikkate alındığında, kırılma noktalarını oldukça iyi belirlemektedir. Ayrıca boyut özelliği nominal anlamlılık düzeyine yakındır ve güç performansı da oldukça yüksek olduğu bilinmektedir (NP, 2010; 724-727). Dolayısıyla tüm değişkenlerin durağan olmadığı belirlendikten sonra, bu değişkenlerin uzun dönemde birlikte hareket edebileceği düşüncesiyle, analizin ikinci kısmı olan yapısal kırılmalı eşbütünleşme testleri kullanılmıştır. Tablo 4'de GH ve HJ testi sonuçları verilmektedir. 
A. E. Çağlar \& M. Mert / Türkiye'de Çevresel Kuznets Hipotezi ve Yenilenebilir Enerji Tüketiminin Karbon Salımı Üzerine Etkisi: Yapısal Kırılmalı Eşbütünleşme Yaklaşımı

Tablo 4. GH ve HJ Eşbütünleşme Testlerinin Sonuçları

\begin{tabular}{|c|c|c|c|c|c|c|c|}
\hline Test & Model & $A D F^{*}$ & $T B$ & $Z_{t}^{*}$ & $T B$ & $Z_{\alpha}^{*}$ & $T B$ \\
\hline \multirow{2}{*}{ GH } & $\mathrm{C}$ & $-5.318 *$ & 2002 & $-5.369 *$ & 2002 & -40.042 & 2002 \\
\hline & $\mathrm{C} / \mathrm{S}$ & $-6.906 * *$ & 2003 & $-6.973 * *$ & 2003 & -53.971 & 2003 \\
\hline HJ & $\mathrm{C} / \mathrm{S}$ & $-8.747 * *$ & $\begin{array}{l}1991- \\
1996\end{array}$ & $-8.831 * *$ & $\begin{array}{l}1991- \\
1996\end{array}$ & -65.010 & $\begin{array}{l}1991- \\
1997\end{array}$ \\
\hline
\end{tabular}

Tablo 4'de GH testinin $A D F^{*}$ ve $Z_{t}^{*}$ test istatistiklerine göre $\% 5$ yanılma düzeyinde eşbütünleşme yoktur sıfır hipotezi reddedilmektedir. Fakat $Z_{\alpha}^{*}$ test istatistiği dikkate alındığında sıfir hipotezi kabul edilmektedir. Bu testin boyut ve güç özellikleri incelendiğinde, $Z_{t}^{*}$ test istatistiği en iyi güç ve boyut özelliklerine sahip olmaktadır. (GH, 1996: 113, 114). Dolayısıyla $Z_{t}^{*}$ test istatistiğine göre $\mathrm{CO}_{2}$, YEN, GSHY ve GSHY ${ }^{2}$ değişkenleri arasında uzun dönemli bir eşbütünleşme ilişkisi olduğu sonucuna ulaşlabilir. GH testinde anlamlı olan kırılma tarihleri incelendiğinde Türkiye ekonomisinde ciddi tahribatlara neden olan 2001 krizinin etkileri görülmektedir.

$\mathrm{HJ}$ testinin sonuçları incelendiğinde ise, $A D F^{*}$ ve $Z_{t}^{*}$ test istatistikleri $\% 5$ anlamlılık düzeyinde sıfır hipotezini reddetmektedir. Fakat $Z_{\alpha}^{*}$ test istatistiği ile sıfır hipotezi kabul edilmektedir. Burada, HJ testinin güç ve boyut özellikleri incelendiğinde, $A D F^{*}$ test istatistiğinin boyut özelliği nominal anlamlılık düzeyine yakın olduğu için boyut bozulmalarının az olduğu görülmektedir. $A D F^{*}$ test istatistiği ile $Z_{t}^{*}$ test istatistiği aynı asimptotik dağılıma sahiptirler. Dolayısıyla $A D F^{*}$ ve $Z_{t}^{*}$ test istatistiklerine göre, ele alınan değişkenler uzun dönemde eşbütünleşik olduğu söylenilebilir. Bu sonuç $\mathrm{GH}$ testinin sonuçları ile tutarlılık göstermektedir. HJ testinde anlamlı bulunan kırılma tarihleri incelendiğinde, 1994 ekonomi krizinin etkileri açık bir şekilde görülmektedir. Dolayısıyla, her iki test sonuçlarına göre de ele alınan değişkenler arasında eşbütünleşme ilişkisi olduğu görülmüştür.

Analizin üçüncü kısmında ise, uzun dönemde YEN, GSYH ve GSYH ${ }^{2}$ değişkenlerinin $\mathrm{CO}_{2}$ sera gazını nasıl etkileyeceğini görmek amacıyla DOLS tahmincisine başvurulmuştur. Eşitlik 21 'de tahmin edilen model verilmiştir.

$\mathrm{CO}_{2 t}=\alpha_{0}+\alpha_{1} G S Y H_{t}+\alpha_{2} G S Y H_{t}^{2}+\alpha_{3} Y E N_{t}+u_{t}$

ÇKE hipotezi çerçevesinde, Eşitlik 21'de $\alpha_{1}$ parametresinin pozitif ve $\alpha_{2}$ parametresinin de negatif olması beklenmektedir. $\alpha_{1}{ }^{\prime}$ in pozitif ve anlamlı olmasi; aynı zamanda $\alpha_{2}$ 'nin negatif ve anlamlı olması $\mathrm{CO}_{2}$ salımının ÇKE'sinde dönüm noktasına kadar artıp sonra azaldığını göstermektedir. Dönüm noktasından sonra ekonomik büyüme, karbon salımında azalma meydana getirmektedir. Ancak $\alpha_{2}$ parametresinin anlamsız olması karbon emisyonunun monoton bir şekilde arttığını göstermektedir. Diğer taraftan yenilenebilir kaynaklı enerji tüketimini gösteren YEN değişkeninin katsayısı olan $\alpha_{3}$ 'ün negatif işaretine sahip olmas1 
beklenmektedir. Çünkü yenilenebilir kaynaklı enerjinin genellikle insan sağlığını ve doğayı olumlu etkilediği bilinmektedir (Bölük ve Mert, 2015; 591). DOLS tahmincisi sonuçları Tablo 5'de verilmiştir.

Tablo 5. DOLS Tahmin Sonuçları

\begin{tabular}{lllll}
\hline Bağımlı Değişken: $\mathrm{CO}_{2}$ & Katsayı & Standart Hata & T-oranı & $P$ değeri \\
\hline GSYH & $0.0012^{* * *}$ & $8.35 \mathrm{E}-05$ & 14.727 & 0.000 \\
GSYH & & $9.23 \mathrm{E}-09$ & -5.899 & 0.000 \\
YEN & $-5.44 \mathrm{E}-08^{* * * *}$ & 0.006 & -2.663 & 0.012 \\
Sabit & $-0.0170^{* *}$ & 0.1943 & -10.514 & 0.000 \\
$*, * *, * * *$ işaretleri katsayıların, sirasılyla .10, .05 ve .01 yanılma düzeylerinde anlamlı olduğunu göstermektedir.
\end{tabular}

Tablo 5 incelendiğinde, GSYH'nın doğaya sera gazı salımını arttırdığ 1 görülmektedir. Fakat ÇKE, gelişmekte olan ülkelerde ilk olarak gelirin düşük seviyelerinde, doğaya sera gazı salımının düşük olacağını söylemektedir. Fakat bir noktaya kadar gelirle birlikte sera gazı salımı da artacaktır. Daha sonra belli bir gelir seviyesine ulaştıktan sonra, gelirle ters orantılı olacak biçimde sera gazı salımı azalacaktır. DOLS sonuçları, GSYH pozitif ve $\mathrm{GSYH}^{2}$ ise negatif olacağını söyleyen ters-U hipotezini de desteklemektedir. Tablo 5'e göre yenilenebilir kaynaklı enerji tüketimi bir $\mathrm{kWh}$ arttığında atmosfere salınan sera gazı yaklaşık olarak 0.02 dolaylarında azalacaktır. Bu sonuç, Türkiye'de yenilenebilir enerji kaynaklarının sera gazı salımını düşürdügünü göstermektedir. Dolayısıyla, kamu kesimi tarafından Türkiye'de yenilenebilir enerji kaynaklarına yönelim özendirilmeli ve gerekli altyapı sağlanmalıdır. Böylece çevreye verilen olumsuz etkiler yenilenebilir enerji kaynağ

\section{SONUÇ}

$\mathrm{Bu}$ çalışmada 1960-2013 yılları arasında kişi başı karbon salımı, yenilenebilir kaynaklı enerji tüketimi ve Çevresel Kuznets Eğrisi hipotezi için kişi başı gayri safi yurt içi hasıla serileri ele alınmış, tek ve çift yapısal kırılmalı birim kök testleriyle beraber yapısal kırılmaya izin veren Gregory Hansen (1996) ve Hatemi-J (2008) eşbütünleşme analizleri ile seriler arasındaki uzun dönem ilişkinin varlığı tespit edilerek dinamik en küçük kareler yöntemi ile uzun dönem denge ilişkisi elde edilmiştir. Tahmin edilen modelde GSYH değişkeninin katsayısının pozitif ve anlamlı, GSYH2 değişkeninin katsayısının negatif ve anlamlı olması Türkiye için örneklem periyodunda Çevresel Kuznets Eğrisi hipotezinin geçerli olduğunu göstermiştir. Bu sonuç Bölük ve Mert (2015) ve Bilgili vd. (2015) çalışmaları ile tutarlılık göstermektedir. Dolayısıyla Türkiye'de milli gelirde görülecek artışlar sonrası belli bir eşik seviyesini geçtikten sonra karbon salımının düşmesi beklenmektedir. Ters $U$ şeklinde belirlenen Kuznets eğrisinin eşik seviyesi, tahmin edilen eşitlik 21 'den $\alpha_{1} /\left|2 \alpha_{2}\right|=11029.41 \$$ olarak elde edilmektedir. Yani Türkiye'de kişi başı gayri safi yurt içi hasılanın 11029.41\$'a ulaşması ile beraber o ana dek artan karbon salımı azalmaya başlayacaktır. Modeldeki yenilenebilir enerji tüketiminin katsayısının negatif ve anlamlı çıkması beklenilen bir sonuç olup Bölük ve Mert'in (2015) çalışmasıyla örtüşmektedir. Bölük ve Mert'in (2015) çalışmasından farklı olarak bu çalışmada incelenen 
A. E. Çă̆lar \& M. Mert / Türkiye'de Çevresel Kuznets Hipotezi ve Yenilenebilir Enerji Tüketiminin Karbon Salımı Üzerine Etkisi: Yapısal Kırılmalı Eşbütünleşme Yaklaşımı

serilerde ve eşbütünleşme ilişkisinde yapısal kırılmalar dikkate alınmıştır. 1994 ve 2001 krizlerinin neden olduğu yapısal kırılmaların etkisinde uzun dönem tahminleri yapılmıştır. Böylelikle tahmin edilen modelin daha sağlam ve güncel olması sağlanmıştır.

Küresel 1sınma ile birlikte sera gazı etkisi araştırmacılar tarafından ilgi çekici duruma gelmiştir. Fosil yakıtların sera gazı miktarındaki artıştan büyük pay sahibi olması bilim insanlarını alternatif enerji konularında araştırma yapmaya yönlendirmiştir. Bunun sonucunda yenilenebilir kaynaklı enerjinin doğaya salınan sera gazı miktarında azalma meydana getirdiği çalışmalarla gösterilmiştir. Ancak bu çalışmaya göre, karbon salımının düşmeye başlayacağı eşik noktasına kadar sera gazı miktarında ciddi artışlar beklenmektedir. Bu noktada çalışmanın önemli bir sonucu olan yenilenebilir kaynaklı enerji, sera gazı salımının azaltması yönünde önemli kanıtlar sunmuştur. Dolayısıyla Türkiye'de yenilenebilir kaynaklı enerji özendirilmeli ve bu alanda ciddi yatırımlar yapılmalıdır.

\section{KAYNAKÇA}

Agras, J., \& Chapman, D. (1999). A Dynamic Approach to the Environmental Kuznets Curve Hypothesis. Ecological Economics. 28(2). 267-277.

Ahmed, K., \& Long, W. (2012). Environmental Kuznets Curve and Pakistan: An Empirical Analysis. Procedia Economics and Finance. 1. 4-13. doi: 10.1016/S2212-5671(12)000032.

Akbostanci, E., Türüt-Aşık, S. \& Tunç, İ. (2009). The Relationship Between Income and Environment in Turkey: Is There an Environmental Kuznets Curve?. Energy Policy. 37. 861-867. doi:10.1016/j.enpol.2008.09.088.

Ang, J. B. (2007). CO2 Emissions, Energy Consumption, and Output in France. Energy Policy. 35(10). 4772-4778. doi:10.1016/j.enpol.2007.03.032

Apergis, N., \& Payne, J. E. (2009). Energy Policy.37(8). 3282-3286. doi:10.1016/j.enpol.2009.03.048.

Arı, A. \& Zeren, F. (2011). CO2 Emisyonu ve Ekonomik Büyüme: Panel Veri Analizi. Celal Bayer $\begin{array}{llll}\text { Üniversitesi } & \text { I.I.B.F. } & \text { Dergisi. } & \text { 37-47. }\end{array}$ www2.bayar.edu.tr/yonetimekonomi/dergi/pdf/C18S22011/37_47.pdf

Azam, M., \& Khan, A. Q. (2016). Testing the Environmental Kuznets Curve Hypothesis: A Comparative Empirical Study for Low, Lower Middle, Upper Middle and High Income Countries. Renewable and Sustainable Energy Reviews.63. 556-567. doi: 10.1016/j.rser.2016.05.052.

Baek, J., Cho, Y., \& Koo, W. W. (2009). The Environmental Consequences of Globalization: A Country-Specific Time-Series Analysis. Ecological Economics. 68(8). 2255-2264. doi: 10.1016/j.ecolecon.2009.02.021.

Başar, S. \& Temurlenk, M.S. (2007). Çevreye Uyarlanmış Kuznets Eğrisi: Türkiye Üzerine Bir Uygulama. Atatürk Üniversitesi IIBFF Dergisi. 21(1). 1-12. dergipark.ulakbim.gov.tr/atauniiibd/article/download/1025003715/1025003544.

Bilgili, F., Koçak, E., \& Bulut, Ü. (2016). The Dynamic Impact of Renewable Energy Consumption on Co2 Emissions: A Revisited Environmental Kuznets Curve Approach. Renewable and Sustainable Energy Reviews. 54. 838-845. doi: 10.1016/j.rser.2015.10.080.

Bölük, G., \& Mert, M. (2014). Fossil \& Renewable Energy Consumption, GHGs (Greenhouse Gases) and Economic Growth: Evidence From a Panel of EU (European Union) Countries. Energy. 74. 439-446. doi: 10.1016/j.energy.2014.07.008.

Bölük, G., \& Mert, M.. (2015). The Renewable Energy, Growth and Environmental Kuznets Curve in Turkey: an ARDL Approach. Renewable and Sustainable Energy Reviews. 52. 587-595. doi: 10.1016/j.rser.2015.07.138. 
Çağlar, A., E. (2015). Yapısal Kırılmalı Birim Kök Testlerinin Küçük Örneklem Özelliklerinin Karşılaş̧tırılması. Pamukkale Üniversitesi Sosyal Bilimler Enstitüsü. Yüksek Lisans Tezi.

Çağlar, M. (2006). Dünya ve Türkiye'de Yenilenebilir Enerji Kaynakları. Türkiye 10. Enerji Kongresi. 1-21. http://www.dektmk.org.tr/pdf/enerji_kongresi_10/mehmetcaglar.pdf

Dam, M. M., Karakaya E. \& Bulut, Ş. (2014). Çevresel Kuznets Eğrisi ve Türkiye: Amprik Bir Analiz. Dumlupinar Üniversitesi Sosyal Bilimler Dergisi, Eyi Özel Sayısı. 85-96.

De Bruyn, S. M., Van den Bergh, J. C. J. M., \& Opschoor, J. B. (1996). Economic Growth and Patterns of Emissions-Reconsidering the Empirical Basis of Environmental Kuznet Curves. http://dare.ubvu.vu.nl/handle/1871/10943.

Dickey, D.A. \& Fuller, W.A. (1979). Distribution of the Estimators for Autoregressive Time Series With a Unit Root. Journal of the American Statistical Association. 7(4). 427-431. doi: $10.2307 / 2286348$.

Dickey, D.A. \& Fuller, W.A. (1981). Likelihood Ratio Statistics for Autoregressive Time Series with a Unit Root. Econometrica: Journal of the Econometric Society. 49(4). 1057-1072. doi: $10.2307 / 1912517$.

Dinda, S. (2004). Environmental Kuznets Curve Hypothesis: A Survey. Ecological Economics. 49/4. 431-455. doi: 10.1016/j.ecolecon.2004.02.011.

Dinda, S., Coondoo, D., \& Pal, M. (2000). Air Quality and Economic Growth: an Empirical Study. Ecological Economics. 34(3). 409-423. doi: 10.1016/S0921-8009(00)00179-8.

Elliot, G. vd. (1996). Efficient Tests for an Autoregressive Unit Root. Econometrica. 64. 813-836. doi: $10.3386 / \mathrm{t} 0130$.

Engle, R.F. \& Granger, C.W. J. (1987). Cointegration and Error-Correction: Representation, Estimation and Testing. Econometrica. 66. 251-276. doi: 10.2307/1913236.

Fodha, M., \& Zaghdoud, O. (2010). Economic Growth and Pollutant Emissions in Tunisia: An Empirical Analysis of the Environmental Kuznets Curve. Energy Policy. 38(2) 1150-1156. doi: 10.1016/j.enpol.2009.11.002.

Gregory, A. W. \& Hansen, B. E. (1996). Residual-Based Tests for Cointegration in Models with Regime Shifts. Journal of Econometrics. 70. 99-126. doi: 10.1016/0304-4076(69)41685-7.

Grossman, G. M., \& Krueger, A. B. (1991). Environmental Impacts of a North American Free Trade Agreement. NBER Working Paper. No. 3914. doi: 10.3386/w3914.

Grossman, G.M., \& Krueger, A.B. (1995). Economic Growth And The Environment. Q. J. Econ. 110. 353-378. doi: 10.3386/w4634.

Güriş, S. \& Elif T. (2011). Çevresel Kuznets Eğrisinin Geçerliliğinin Panel Veri Modelleriyle Analizi. Trakya Üniversitesi Sosyal Bilimler Dergisi. 13(2). 173-190.

Haisheng, Y., Jia, J., Yongzhang, Z., \& Shugong, W. (2005). The Impact on Environmental Kuznets Curve by Trade and Foreign Direct Investment in China. Chinese Journal of Population Resources and Environment. 3(2). 14-19. doi: 10.1080/10042857.2005.10677410.

Halicioglu, F. (2009). An Econometric Study of CO2 Emissions, Energy Consumption, Income and Foreign Trade in Turkey. Energy Policy.37(3). 1156-1164. doi: 10.1016/j.enpol.2008.11.012.

Hatemi-J, A. (2008). Tests for Cointegration with Two Unknown Regime Shifts with an Application to Financial Market Integration. Empirical Economics. 35. 497-505. doi: 10.1007/s00181007-0175-9.

Iwata, H., Okada, K., \& Samreth, S. (2010). Empirical Study on the Environmental Kuznets Curve for $\mathrm{CO} 2$ in France: the Role of Nuclear Energy. Energy Policy. 38(8). 4057-4063. doi: 10.1016/j.enpol.2010.03.031.

Jalil, A., \& Mahmud, S. F. (2009). Environment Kuznets Curve for CO2 Emissions: A Cointegration Analysis for China. Energy Policy. 37(12). 5167-5172. doi:10.1016/j.enpol.2009.07.044.

Kim, H. S., \& Baek, J. (2011). The Environmental Consequences of Economic Growth Revisited. Economics Bulletin. 31(2). 1-13. http://www.accessecon.com/Pubs/EB/2011/Volume31/EB-11-V31-I2-P113.pdf.

Kuznets, S. (1955). Economic Growth and Income Inequality. American Economic Review. 49 1-28. http://www.jstor.org/stable/pdf/1811581.pdf. 
A. E. Çağlar \& M. Mert / Türkiye'de Çevresel Kuznets Hipotezi ve Yenilenebilir Enerji Tüketiminin Karbon Salımı Üzerine Etkisi: Yapısal Kırılmalı Eşbütünleşme Yaklaşımı

Kwiatkowski, D., P.C.B. Phillips, P. Schmidl, \& Y. Shin. (1992). Testing The Null Hypothesis of Stationarity Against The Alternative of A Unit Root: How Sure Are We That Economic Time Series Have A Unit Root?. Journal of Econometrics. 54. 159-178. doi:10.1016/03044076(92)90104-Y.

Lau, L. S., Choong, C. K., \& Eng, Y. K. (2014). Investigation of the Environmental Kuznets Curve for Carbon Emissions in Malaysia: Do Foreign Direct Investment and Trade Matter?. Energy Policy. 68. 490-497. doi: 10.1016/j.enpol.2014.01.002.

Lise, W., \& Van Montfort, K., (2007). Energy Consumption and GDP in Turkey: Is There a CoIntegration Relationship?. Energy Economics. 29(6). 1166-1178. doi: 10.1016/j.eneco.2006.08.010.

Managi, S., \& Jena, P. R. (2008). Environmental Productivity and Kuznets Curve in India. Ecological Economics. 65(2) 432-440. doi: $\mathrm{g} / 10.1016 /$ j.ecolecon.2007.07.011.

Mert, M., \& Bölük, G. (2016). Do Foreign Direct Investment and Renewable Energy Consumption Affect the CO2 Emissions? New Evidence from a Panel ARDL Approach to Kyoto Annex Countries. Environ Sci Pollut Res. doi: 10.1007/s11356-016-7413-7.

Narayan, P.K. \& Popp, S. (2010). A New Unit Root Test with Two Structural Breaks in Level and Slope at Unknown Time. J. Appl. Statatistic. 37(9). 1425-1438. doi: $10.1080 / 02664760903039883$.

Nelson, C.R. \& Plosser, C.I. (1982). Trends and Random Walks in Macroeconomic Time Series. Journal of Monetary Economics. 10. 139-162.

Ng, S. \& Perron, P. (1995). Unit Root Tests in ARMA Models with Data Dependent Methods for the Selection of the Truncation Lag. Journal of the American Statistical Association. 90(429). 268-281.

Panayotou, T. (1993). Empirical Tests and Policy Analysis of Environmental Degradation at Different Stages of Economic Development. ILO Technology and Employment Programme Working Paper. WP238.

Perron, P., (1989). The Great Crash, the Oil Price Shock, and the Unit Root Hypothesis. Econometrica. 57(6). 1361-1401. doi: 10.2307/1913712.

Phillips, P. C. (1987). Time Series Regression with a Unit Root. Econometrica: Journal of the Econometric Society. 277-301. doi: 10.2307/1913237.

Phillips, P. \& Perron, P. (1988). Testing For A Unit Root in Time Series Regression. Biometrica. 75(2). 335-346. doi: 10.1093/biomet/75.2.335.

Saboori, B., Sulaiman, J., \& Mohd, S. (2012). Economic Growth and CO2 Emissions in Malaysia: a Cointegration Analysis of the Environmental Kuznets Curve. Energy Policy. 51. 184-191. doi: 10.1016/j.enpol.2012.08.065.

Selden, T. M., \& Song, D. (1994). Environmental Quality and Development: Is There a Kuznets Curve for Air Pollution Emissions?. Journal of Environmental Economics and Management. 27(2). 147-162. doi:10.1006/jeem.1994.1031.

Shahbaz, M., Mutascu, M., \& Azim, P. (2013). Environmental Kuznets Curve in Romania and the Role of Energy Consumption. Renewable and Sustainable Energy Reviews. 18. 165-173. doi: 10.1016/j.rser.2012.10.012.

Soytas, U., Sari, R., \& Ewing, B. T. (2007). Energy Consumption, Income, and Carbon Emissions in the United States. Ecological Economics. 62(3). 482-489. doi: 10.1016/j.ecolecon.2006.07.009.

Stern, D. I., (2004). The Rise and Fall of the Environmental Kuznets Curve. World Development. 32(8). 1419-1439. doi: 10.1016/j.worlddev.2004.03.004.

Stern, D. I., Common, M. S., \& Barbier, E. B. (1996). Economic Growth and Environmental Degradation: the Environmental Kuznets Curve and Sustainable Development. World Development. 24(7). 1151-1160. doi:10.1016/0305-750X(96)00032-0.

Stock, J.H. \& Watson M. (1993). A Simple Estimator Of Cointegrating Vectors in Higher Order Integrated Systems. Econometrica. 61. 783-820. doi: 10.2307/2951763. 
Suri, V., \& Chapman, D. (1998). Economic Growth, Trade and Energy: Implications for the Environmental Kuznets Curve. Ecological Economics. 25(2). 195-208. doi: 10.1016/S0921-8009(97)00180-8.

WWF, (2011). Yenilenebilir Enerji Geleceği ve Türkiye. WWF Raporu. http://awsassets.wwftr.panda.org/downloads/wwftr_yenilenebilirenerjigelecegiveturkiye.p df.

Zivot, E. \& Andrews D.W.K. (1992). Further Evidence on the Great Crash, the Oil Price Shock and the Unit Root Hypothesis. Journal of Business and Economic Statistics. 10(3). 251-270. doi: $10.2307 / 1391541$.

\section{SUMMARY}

Fossil fuel energy consumption is known to increase the effect of greenhouse gases in nature. Thus, the destruction of nature becomes inevitable. Therefore, the world, is faced with problems such as ocean levels rise, climate change, biodiversity (Sweeney, 2000:20). However, renewable energy is considered as a clean energy in the literature. Recently in the studies, it is emphasized renewable energy is inexhaustible while fossil based energy is exhaustible (San et al., 2014; Sims et al., 2003). Renewable energy require a serious investment both in infrastructure and in superstructure. Countries that demanding to use renewable energy must be of a certain level economically. In the light of the discussions mentioned above, in the literature the theory explaining the relationship corbon emission and revenue, square of revenue and renewable energy based energy consumption is known as Environmental Kuznets Curve. Some researchers included in the model the fossil based energy consumption, financial development, foreign direct investment as variables.

In this study, the answer of how to get rid of the negative conditions of enviorement is looked into. For this purpose the Environmental Kuznets Curve hypothesis is commonly used in the literature. To test this hypothesis, out of cointegration tests in the presence of structural break, Gregory ve Hansen (1996) single break and Hatemi-J two break tests are used. In accordance with the Environmental Kuznets Curve hypothesis in the generated model after determining presence of cointegration relationship, then to be able to get long-term coefficients Dynamic Least Squares Estimator is used. According to the results of the Dynamic Least Squares Estimator, coefficient of GSYH variable is positive and significant while the coefficient of GSYH2 variable is negative and significant. According to these results for the environmental Kuznets curve hypothesis in Turkey the sampling period is valid. This results demonstrates consistency with Boluk and Mert (2015) and Bilgili et al. (2015). Therefore, aftermath increases in GDP in Turkey after passing the threshold level it is expected to drop of carbon emissions. Inverted U-shaped Kuznets curve threshold level is estimated using Eq. 21 as $\alpha_{1} /\left|2 \alpha_{2}\right|=11029.41$. So along with Turkey's gross domestic product per person acquisition to $11029.41 \$$, increasing carbon emissions will start to decline until then.

In the literature, it is observed that renewable energy sources doesn't increase carbon emissions, reduces contrast. In the study within the framework of Environmental Kuznets Curve hypothesis we investigated whether or not the usage of renewable energy has any influence on carbon emissions. In the obtained results, 
when a $\mathrm{kWh}$ of renewable energy consumption increases, it is observed that greenhouse gas released into the atmosphere reduce around 0.02 . Therefore, in Turkey it is observed that renewable energy dropped greenhouse gas emissions. In the study it is observed that on Environmental Kuznets curve is inverted Ushaped. As a result, national income in Turkey increases as much as $\$ 11029.41$, carbon emission increases too. But when $\$ 11029.41$ threshold exceeded carbon emission will begin to fall. From these results, it is recommended for policymakers to increase renewable energy in Turkey. But it shouldn't be forgotten that renewable energy emerge as a result of cost. 